\title{
In vitro bond strength of treated direct-bonding metal bases
}

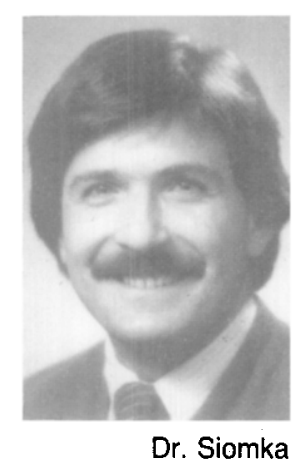

\author{
Leon V. Siomka, D.D.S., M.S., and John M. Powers, Ph.D.** \\ Ann Arbor, Mich.
}

\begin{abstract}
Three types of direct-bonding metal bases were used to determine the effect of five commercial surface treatments on in vitro tensile bond strength. The proprietary treatments were etching, silanation, surface activation, etching plus silanation, and etching plus surface activation. Nontreatment was used as a control. The bases were of the mesh, photo-etched, and grooved types. Bases were loaded with a no-mix adhesive to plastic substrates. The grooved base had the highest bond strength with no treatment. Etching improved the bond strength of the grooved bracket by $56 \%$. Silanation improved the bond strength of the mesh bracket by $28 \%$. Surface treatments did not improve the bond strength of the photo-etched bracket.
\end{abstract}

Key words: Bond strength, brackets, adhesives, etching, silanation

$\mathrm{T}$ he use of composite adhesives in conjunction with acid-etched enamel has made direct bonding of orthodontic brackets practical. When direct-bonding metal bases are used, the failure site has been identified as the adhesive-base interface, both in vitro and in vivo, if the tooth has been prepared properly. ${ }^{1-4}$ This failure site has been observed for a variety of mesh, photoetched, and perforated bases ${ }^{4}$ and appears to be independent of the adhesive. ${ }^{3}$ Recently, several commercial surface treatments have become available to enhance bonding of adhesives to metal brackets.

The purpose of this study was to determine the effect of five commercial surface treatments, including etching, silanation, and surface activation, on the in vitro tensile bond strength of three direct-bonding metal bases.

\section{MATERIALS AND METHODS}

The five proprietary treatments evaluated were silanation (S), etching (E), activation (A), etching plus silanation (SE), and etching plus activation (AE). (Explicit details of the various surface treatments are not available from the companies providing the services.)
Nontreatment $(\mathrm{N})$ was used as a control. Silanation and etching were done commercially.* Surface activation was done with a commercial unit. $\dagger$

The three commercial metal base designs tested were mesh (MM), $\ddagger$ photoetched (ML), $\S$ and grooved (DL).\| The nominal area of each base was measured by planimetry $f$ of enlarged photographs of the bases.

The metal bases were bonded to plastic cylinders with a filled diacrylate no-mix adhesive.\# Liquid primer was painted on the plastic substrate and the bracket base. The paste then was placed on the primed base, and the bracket was placed firmly on the plastic substrate. Each sample was examined optically, and any adhesive overlapping the base was removed. The bonded specimens were stored for 24 hours in water at $37^{\circ} \mathrm{C}$ before testing. Five samples for each of the six conditions were tested.

Tie wires** were attached to the wings of the brackets so that the load would be applied directly over the center of the bracket. The samples were placed in a loading jig $^{5}$ that allowed them to be aligned so as to minimize shear forces during tensile loading. The tests were performed on a testing machine $\dagger^{\dagger}$ at a crosshead

Based on a thesis submitted in partial fulfillment of the requirements for the Master's degree in the Horace H. Rackham School of Graduate Studies at the University of Michigan, 1984.

Correspondence concerning this article should be directed to Dr. John M. Powers, School of Dentistry, University of Michigan, Ann Arbor, MI 48109 1078, (313) 764-1530.

*Orthodontist practicing in Northville Township, Mich.

**Professor of Dentistry, Department of Dental Materials, School of Dentistry, University of Michigan

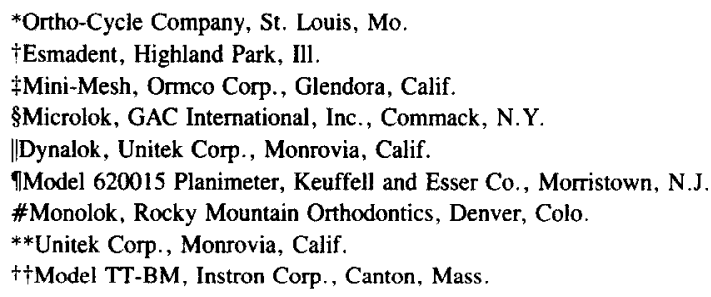




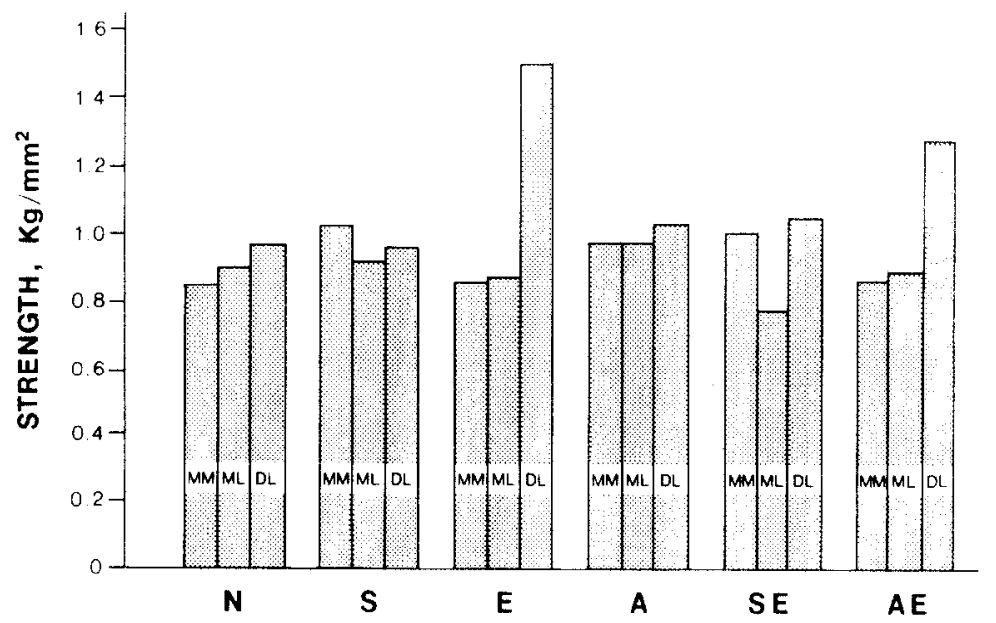

Fig. 1. Mean tensile bond strength for combinations of bases and surface treatments.

speed of $0.2 \mathrm{~cm}$ per minute. The force $(\mathrm{L})$, in kilograms, required to break the bond was recorded. The bond strength (BS), in $\mathrm{kg} / \mathrm{mm}^{2}$, was calculated as $\mathrm{BS}=\mathrm{L}$ divided by the nominal area of the base. Bond failure sites were examined optically and identified as bracketadhesive, cylinder-adhesive, or combined failures. Surface morphology was examined with a scanning electron microscope.

Means and standard deviations were determined. Data were analyzed by a two-way analysis of variance, ${ }^{6}$ and means were ranked by a Tukey interval ${ }^{7}$ calculated at the $95 \%$ level of confidence. Differences between two means that were larger than the Tukey interval were statistically significant.

\section{RESULTS}

Table I lists mean values and standard deviations of the tensile bond strength for bases MM, ML, and DL under the six conditions. The mean values are shown in bar graph form in Fig. 1. The Tukey intervals for comparisons among means of bases and treatments were 0.08 and $0.13 \mathrm{~kg} / \mathrm{mm}^{2}$, respectively. The interaction between base and treatment was statistically significant at the $95 \%$ level of confidence.

Mean tensile bond strengths ranged from 0.83 to $1.09 \mathrm{~kg} / \mathrm{mm}^{2}$ for base MM, 0.78 to $0.96 \mathrm{~kg} / \mathrm{mm}^{2}$ for base ML, and 0.94 to $1.50 \mathrm{~kg} / \mathrm{mm}^{2}$ for base $\mathrm{DL}$. In the untreated condition, base DL had a higher bond strength than MM but was not statistically different from ML. Treatments $S$ and SE showed significant increases in bond strength for base MM. Treatments E, $\mathrm{SE}$, and $\mathrm{AE}$ showed significant increases in bond strength for base $\mathrm{DL}$ with treatment $\mathrm{E}$ having the highest value. None of the treatments significantly increased the bond strength of base ML. Locations of failure sites were at the base-adhesive interface with the exception of base DL - treatment E, which had $40 \%$ failures at the cylinder-adhesive interface.

\section{DISCUSSION}

For evaluation of the bases and surface treatments, a single adhesive of the no-mix variety was used. Other no-mix adhesives would be expected to give similar results, except possibly with brackets that had deep grooves or undercuts. Evans ${ }^{8}$ has shown that there is a decrease in bond strength of the no-mix adhesives as the thickness between the bracket and the substrate increases up to $0.5 \mathrm{~mm}(0.020$ inch). The adhesive used in this study was effective below a thickness of 0.25 $\mathrm{mm}$. The tensile strength of the adhesive was not determined but is expected to be no more than $4.7 \mathrm{~kg} /$ $\mathrm{mm}^{2}$, as reported for similar adhesives by Faust and associates. $^{3}$

The bond strength of base DL with treatment $\mathrm{E}$ increased by $56 \%$, whereas the bond strengths of bases $M M$ and ML were not affected significantly by this treatment as compared with the nontreated condition. Treatment $\mathrm{E}$ used an acid solution to roughen the surfaces of the bases chemically to create a larger surface area for mechanical retention of the adhesive. Each base responded differently to this etching process. Base DL showed a dramatic change in its morphology (Fig. 2), whereas bases MM and ML showed no perceptible changes. These varied responses to etching may be caused by differences in composition of the alloy of each base. Different etching patterns could have resulted if different etchants had been used.

The bond strength of base MM with treatment $S$ increased $28 \%$, whereas the bond strengths of bases ML and DL were not affected significantly by this treat- 
Table l. Mean values and standard deviations of tensile bond strength $\left(\mathrm{kg} / \mathrm{mm}^{2}\right)$ for bases $\mathrm{MM}$, $\mathrm{ML}$, and DL

\begin{tabular}{c|c|c|c}
\hline Treatment & $M M$ & $M L$ & $D L$ \\
\hline $\mathrm{N}$ & $0.85^{*}$ & 0.89 & 0.96 \\
& $(0.06)$ & $(0.10)$ & $(0.19)$ \\
$\mathrm{S}$ & 1.09 & 0.91 & 0.94 \\
& $(0.13)$ & $(0.05)$ & $(0.10)$ \\
$\mathrm{E}$ & 0.86 & 0.87 & 1.50 \\
& $(0.10)$ & $(0.07)$ & $(0.10)$ \\
$\mathrm{A}$ & 0.96 & 0.96 & 1.07 \\
& $(0.05)$ & $(0.07)$ & $(0.07)$ \\
$\mathrm{SE}$ & 0.99 & 0.78 & 1.14 \\
& $(0.22)$ & $(0.07)$ & $(0.15)$ \\
$\mathrm{AE}$ & 0.83 & 0.86 & 1.24 \\
& $(0.09)$ & $(0.04)$ & $(0.25)$ \\
\hline
\end{tabular}

* Mean of five replications with standard deviations in parentheses. Tukey intervals for comparing the bases and treatments were 0.08 and $0.13 \mathrm{~kg} / \mathrm{mm}^{2}$, respectively.

ment. Treatment $S$ used a silane coupling agent dissolved in methanol to promote an increase in wetting of the base and bonding by the adhesive. Silanation appears to have improved wetting of the mesh base to allow better penetration of the resin into undercut areas; however, this treatment did not appear to promote chemical bonding of the adhesive to the base. If silanation had proved very effective, long-term storage would have been advisable because silane bonds can be hydrolyzed on storage in water. No changes in surface morphology of the bases were apparent at $80 \times$ magnification.

Surface activation (treatment A) is an electrochemical process used to remove oil, dust, and thin oxidation films from alloy surfaces that might inhibit bonding. All three bases showed increases in bond strength, ranging from $8 \%$ to $13 \%$, but these increases were not significant statistically. No changes in surface morphology of the bases were apparent at $80 \times$ magnification. This treatment may be more effective on contaminated brackets than on new ones.

Combining silanation and activation treatments with the etching treatment proved to be less effective than etching or silanation alone for bases DL and MM, respectively.

It appears that conditioning of bases by surface treatments, such as etching, silanation, and surface activation, is strongly dependent upon the composition and morphology of the base.

The clinical significance of this study is that basecement bond strength can be improved by commercial conditioning of certain bases. It would be desirable for companies that provide surface treatments to inform

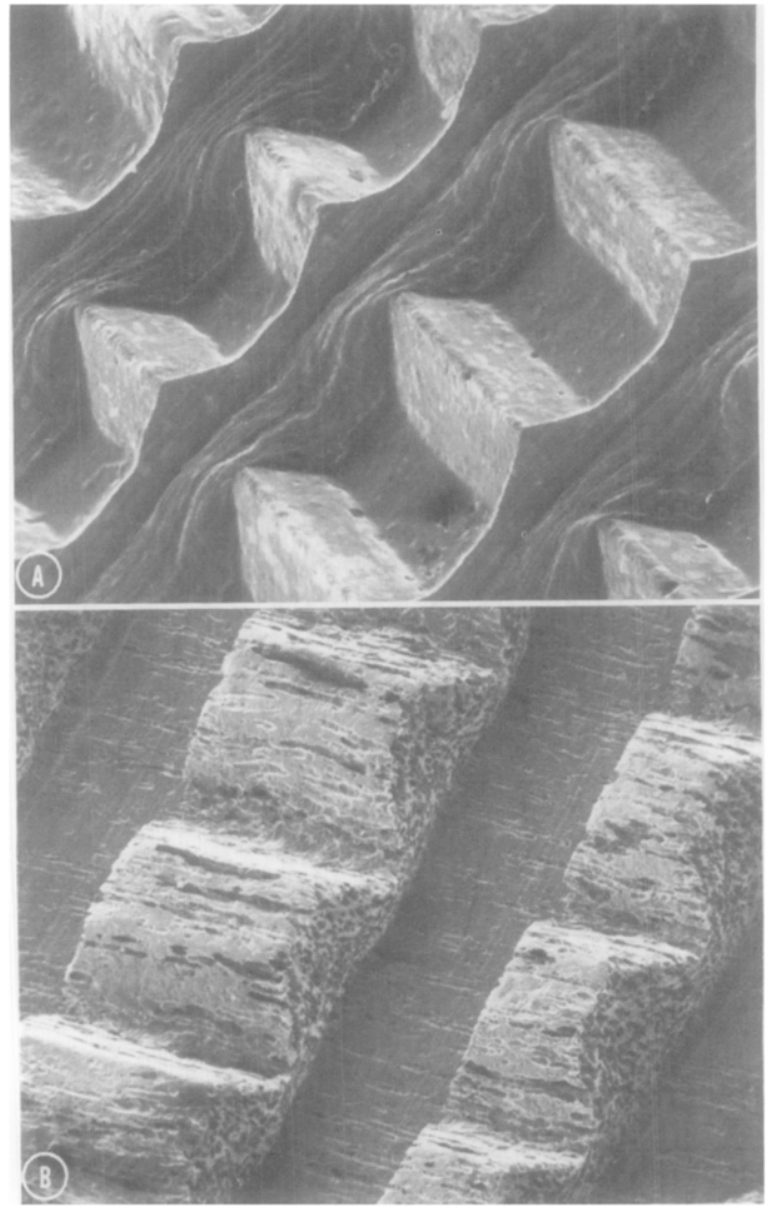

Fig. 2. Scanning electron photomicrographs of base DL in untreated condition (A) and in etched condition (B).

orthodontists concerning bases that can be modified successfully by a specific treatment.

\section{CONCLUSIONS}

1. Base DL had the highest in vitro tensile bond strength in the nontreatment condition, although its strength was not statistically different from that of ML. The strength of bases ML and MM was not significantly different.

2. Silanation and silanation plus etching treatments significantly increased bond strength of base MM, with the silanation treatment having the greater value.

3 . Etching, etching plus silanation, and etching plus surface activation significantly increased the bond strength of base DL, with etching having the greatest value. Etching changed the surface morphology of base DL but not of the other bases.

4. None of the treatments were effective in increasing the bond strength of base ML.

The authors gratefully acknowledge the cooperation of 
the following companies in providing commercial products or services: Ormco Corp., GAC International, Inc., Unitek Corp., Rocky Mountain Orthodontics, Esmadent, and OrthoCycle Co.

\section{REFERENCES}

1. Lee HL, Orlowski JA, Enabe E, Rogers BJ: In vitro and in vivo evaluation of direct-bonding orthodontic bracket systems. J Clin Orthod 8: 227-238, 1974

2. Reynolds IR, von Fraunhofer JA: Direct bonding of orthodontic attachments to the teeth: the relation of adhesive bond strength to gauze mesh size. Br J Orthod 3: 91-95, 1976.

3. Faust JB, Grego GW, Fan PL, Powers JM: Penetration coefficient, tensile strength, and bond strength of thirteen direct bonding orthodontic cements. Ам J ORTHOD 73: 512-525, 1978.

4. Dickinson PT, Powers JM: Evaluation of fourteen direct-bonding orthodontic bases. AM J ORTHOD 78: 630-639, 1980
5. Eden GT, Craig RG. Peyton FA: tevaluation of a tensile test Ior direct filling resins. J Dent Res 49: 428-434, 1970.

6. University of Michigan Statistical Research I ahoratory: A manual of elementary statistics using MIDAS. Ann Arbor, 1975. Statistical Research Laboratory.

7. Guenther WC: Analysis of variance. Englewood Cliffs, N.I. 1964, Prentice-Hall, Inc.

8. Evans LB: Factors affecting bond strength of no-mix orthodontic adhesive systems, Master's thesis. Ann Arbor, 1984, University of Michigan School of Dentistry

Reprint requests to:

Dr. John M. Powers

Department of Dental Materials

University of Michigan School of Dentistry

Ann Arbor, MJ 48109-1078 